\title{
Stability Analysis of Maize Cultivars Adapted to Tropical Environments Using AMMI Analysis
}

\author{
M. OyeKunle ${ }^{1 *}$, A. MenkiR ${ }^{2}$, H. Mani ${ }^{3}$, G. Olaoye ${ }^{4}$, I.S. Usman ${ }^{1}$, S.G. Ado ${ }^{1}$, U.S. Abdullahi ${ }^{1}$, \\ H.O. Ahmed ${ }^{1}$, L.B. Hassan ${ }^{1}$, R.O. Abdulmalik ${ }^{1}$ and H. AbUbaKar ${ }^{1}$ \\ ${ }^{1}$ Department of Plant Science, Ahmadu Bello University, Zaria, Kaduna State, Nigeria \\ ${ }^{2}$ International Institute of Tropical Agriculture (IITA), IITA (UK) Ltd, Carolyn House, \\ 26 Dingwall Road, Croydon CR9 3EE, UK \\ ${ }^{3}$ Department of Agronomy, Ahmadu Bello University, Zaria, Kaduna State, Nigeria \\ ${ }^{4}$ Department of Agronomy, University of Ilorin, Kwara State, Nigeria
}

(Received 5 May 2016; Accepted 29 August 2016)

\begin{abstract}
Genotype $\times$ environment interactions complicate selection of superior genotypes for narrow and wide adaptation. Eighteen tropically-adapted maize cultivars were evaluated at six locations in Nigeria for 2 yrs to (i) identify superior and stable cultivars across environments and (ii) assess relationships among test environments. Environment and genotype $\times$ environment interactions (GEI) were significant $(P<0 \cdot 05)$ for grain yield. Environments accounted for $63.5 \%$ of the total variation in the sum of squares for grain yield, whereas the genotype accounted for 3.5\% and GEI for 32.8\%. Grain yield of the cultivars ranged from $2292 \mathrm{~kg}$ $\mathrm{ha}^{-1}$ for DTSTR-W SYN2 to $2892 \mathrm{~kg} \mathrm{ha}^{-1}$ for TZL COMP4 C3 DT C2 with an average of $2555 \mathrm{~kg} \mathrm{ha}^{-1}$. Cultivar DT SYN2-Y had the least additive main effect and multiplicative interaction (AMMI) stability value of 7.4 and hence the most stable but low-yielding across environments. AMMI biplot explained $90.5 \%$ and classified cultivars and environments into four groups each. IWD C3 SYN F3 was identified as the high-yielding and stable cultivar across environments. ZA15, ZA14, BK14, BK15 and IL15 had environment mean above the grand mean, while BG14, BG15, LE14, LE15, IL14, LA14 and LA15 had mean below the grand mean. ZA, BK, BG, LE and LA were found to be consistent in ranking the maize cultivars. However, Zaria, Birnin Kudu, and Ilorin were identified as the best test locations and could be used for selecting the superior maize cultivars. The identified high-yielding and stable cultivar could be further tested and promoted for adoption to contribute to food insecurity in Nigeria.
\end{abstract}

Keywords: AMMI stability value, genotype $\times$ environment interaction, grain yield, maize cultivars, multiple environments 


\section{Introduction}

Maize (Zea mays L.) is the third most important cereal crop in the word after wheat and rice. It is the widest growing cereal crop in Nigeria (FAOSTAT 2016) due to its high productivity, wide adaptation and relative ease of cultivation, processing, storage and transportation. It is planted on an estimated area of 5.8 million hectares in Nigeria with an annual production of 10.8 million tons in 2014 (FAOSTAT 2016). Maize accounts for about $15 \%$ of the total calorific intake of the rural dwellers (Badu-Apraku et al. 2011a). The demand for maize has considerably increased due to its potential usefulness as food, livestock feed and raw materials for industrial products.

As a result of these, it has been used to combat the food security challenges posed by the population increase in West Africa (Byerlee and Eicher 1971). Therefore, strategies to increasing maize productivity is the major priority for African agricultural development to reduce poverty and hunger and thus lead to proposed African Green Revolution (Ejeta 2010).

Stability and adaptability of cultivars are best assessed by evaluating the cultivars in different environments and ecological regions. Changes in environments affect both crop growth and grain yield due to significant genotype $\times$ environment interactions (GEI) (Reddy et al. 2011; Xu et al. 2013). Results of multi-location trials (MET) have demonstrated the existence of GEI (Fakorede and Adeyemo 1986; Badu-Apraku et al. 2003, 2008, 2011a, b). The presence of a significant GEI complicates the selection of superior cultivars and the best testing sites for identifying superior and stable genotypes. This necessitates extensive testing of cultivars in multiple environments over several years before cultivars are recommended for release. Grain yield being a complex trait routinely exhibit GEI, thus requires genotype evaluation in MET in the advanced stages of selection (Kang et al. 2004; Fan et al. 2007). Analysis of MET data revealed that some cultivars are well adapted to specific ecological regions (Gauch and Zobel 1997; Yan 2010). Therefore, selection of suitable genotypes and testing sites is crucial to the success of a plant breeding program.

Several stability statistics used to partition GEI include regression analysis (Gauch and Zobel 1988), multivariate analysis (Westcoff 1987), cluster analysis (Crossa et al. 1991), genotype main effect plus genotype $\times$ environment (GGE) biplot (Yan 2001) and additive main effect and multiplicative interaction (AMMI) (Gauch 1992). However, both GGE and AMMI analyses are the most frequently used in analyzing GEI pattern of multi-environment data set. AMMI analysis is capable of detecting GEI in a multi-dimensional space and presents the interaction visually using a biplot. AMMI has been used to analyse GEI in wheat (Crossa et al. 1991; Chang and Chai 2006), rice (Liu et al. 2002), and maize (BaduApraku et al. 2011a, 2011b). Therefore, understanding the GEI between intermediate maturing maize cultivars and testing sites for evaluating regional trials in Nigeria is very important for evaluating the stability and suitability of the cultivars and environments. Therefore, the objectives of the present study were to (i) identify superior and stable cultivars across environments and (ii) assess relationships among test environments. 


\section{Materials and Methods}

Eighteen drought tolerant intermediate maturing maize cultivars were evaluated at six locations in Nigeria in 2014 and 2015. The trials were conducted under rainfed conditions when the rains had become fully established at each experimental site. The trials were evaluated at all sites using randomized complete block design with three replications. Each experimental plot consisted of two rows 5-m long, with inter-row spacing of $0.75 \mathrm{~m}$ and intra-row spacing of $0.5 \mathrm{~m}$. Three seeds were planted per hill and later thinned to two plants/hill, giving a final population density of 53,333 plants/ha. A compound fertilizer NPK 15:15:15 was applied at the rate of $60 \mathrm{~kg} \mathrm{~N}$, at two weeks after planting in all the experiments. An additional $60 \mathrm{~kg} \mathrm{~N} \mathrm{ha}^{-1}$ urea was top-dressed at six weeks after planting. The experiment was kept weed-free by applying $51 \mathrm{ha}^{-1}$ each of a mixture of gramoxone as a foliar contact herbicide and primextra as a pre-emergence herbicide. Subsequently, manual weeding was done as necessary to ensure the trials were weed-free.

Observations were made on each plot for days to anthesis and silking as the number of days from planting to when $50 \%$ of the plants had shed pollen and had emerged silks, respectively. Anthesis-silking interval (ASI) was determined as the difference between $50 \%$ silking and anthesis. Plant and ear heights were measured as the distance from the base of the plant to the height of the first tassel branch and the node bearing the upper ear, respectively. Husk cover was rated on a scale of 1 to 5 , where $1=$ husk tightly arranged and extended beyond the ear tip and $5=$ ear tips exposed. Plant aspect was scored on a scale of 1 to 5 , where $1=$ excellent plant type and $5=$ poor plant type. Ear aspect was based on a scale of 1 to 5 , where $1=$ clean, uniform, large, and well-filled ears and $5=$ ears with undesirable features. Number of ears per plant (EPP) was obtained by dividing the total number of ears per plot by the number of plants harvested. Grain yield was computed based on $80 \%$ (800 g grain $\mathrm{kg}^{-1}$ ear weight) shelling percentage and adjusted to $150 \mathrm{~g} \mathrm{~kg}^{-1}$ moisture content.

Combined analysis of variance (ANOVA) across environments was performed on plot means for grain yield and other measured traits with PROC GLM in SAS using a RANDOM statement with the TEST option (SAS Institute 2002). In the combined ANOVA, each location and year was considered as environment, subsequently environments and replicates were considered as random factors while entries were considered as fixed effects. Subsequently, yield data were subjected to AMMI analysis to assess the relationships among cultivars, environments and $\mathrm{G} \times \mathrm{E}$ interaction. The AMMI model was described by Zobel et al. (1988), Gauch and Zobel (1988) and Crossa (1990). The GGE biplot software Windows application that fully automates biplot analysis (Yan 2001) was used for the AMMI analysis. AMMI stability value (ASV) (Sabaghnia et al. 2008) was estimated for each cultivar as:

$$
\operatorname{ASV}\left(i^{\text {th }} \text { Genotype }\right)=\left\{\left[(\mathrm{SSPCA} 1 / \mathrm{SSPCA} 2) \times \mathrm{PCA} 1 \text { score }_{i}\right]^{2}+\left(\mathrm{PCA} 2 \text { score }_{i}\right)^{2}\right]^{1 / 2}
$$

where SSPCA1 and SSPCA2 are the sum of squares of principal component analysis 1 and 2, respectively; PCA1 and PCA2 are principal component analysis 1 and 2, respectively. 


\section{Results}

The results of combined analysis of variance across 12 environments for the 18 cultivars revealed that test environments $(\mathrm{E})$ were significantly $(P<0.01)$ different for all measured traits. In contrast, genotypes $(\mathrm{G})$ were not significantly different for all measured traits. However, $\mathrm{G} \times \mathrm{E}$ interaction was significantly $(P<0.05)$ different for only grain yield. Decomposition of grain yield GEI into first interaction principal component analysis (IPCA1), second interaction principal component analysis (IPCA2) and residuals revealed that IPCA1 was significantly $(P<0.01)$ different for all measured traits except days to anthesis while IPCA2 was significantly $(P<0.01)$ different for grain yield, ASI, plant and ear aspects (Table 1). The test environments contributed about $63.5 \%$ of the total variation in grain yield, genotypes accounted for about 3.5\% and GEI sources of variation accounted for about $32.8 \%$ (Table 1). The contribution of environments to the total variation was nearly twice that of GEI and eighteen times that of genotypes. However, the contribution of locations to the environmental variation was $92.7 \%$, year accounted for $0.3 \%$, and location $\times$ year interaction accounted for $7.0 \%$ (data not shown). The IPCA1 accounted for about $40.8 \%$ of the GEI sum of squares, while IPCA2 accounted for $25.6 \%$, thus, IPCA1 and IPCA2 together accounted for $66.4 \%$ of the total variation of the GEI sum of squares (Table 1). Grain yield of the cultivars across the environments ranged from $2292 \mathrm{~kg} \mathrm{ha}^{-1}$ for DTSTR-W SYN2 to $2892 \mathrm{~kg} \mathrm{ha}^{-1}$ for TZL COMP4 C3 DT C2 with an average of $2555 \mathrm{~kg} \mathrm{ha}^{-1}$ (Table 2). The least significant difference (LSD) values obtained in the present study were relatively high for some of the traits. Cultivar DT SYN2-Y had the least AMMI stability value of 7.4 while cultivar TZL COMP1-W C6/DT-SYN-1-W had the highest (57.84).

The significant GEI for grain yield inform the use of AMMI analysis to decompose the GEI to determine the yield performance and stability of the intermediate maturing maize

cultivars. The AMMI biplot with the genotype and environment main effects for grain yield on the $\mathrm{x}$-axis and the IPCA1 scores on the y-axis is presented in Fig. 1. The vertical line is the grand mean for grain yield and the horizontal line (y-ordinate) represents the IPCA1 value of zero. Genotypes close to the horizontal line have small interactions and are considered to be more stable than those farther from it. The results of the AMMI analysis of the 18 cultivars evaluated in 12 environments in Nigeria showed that E accounted for $71.6 \%$ of the total variation in the sum of squares for grain yield, while the $\mathrm{G}$ and IPCA 1 sources of variation accounted for $4 \%$ and $15 \%$ of the total variation, respectively. Thus, a total of $90.5 \%$ of the treatment sum of squares were captured by the AMMI biplot, thus making it effective in explaining both the main effects and providing insight into the GEI. The biplot revealed large variability among the 12 test environments and the narrow yield range among the 18 cultivars. Cultivars G12, G18, G13 and G9 were characterized by IPCA1 scores near zero and therefore had small interaction with the environments and similar grain yield response (below the grand mean). Cultivar G16 was characterized by IPCA1 scores near zero and therefore had small interaction with the environments and grain yield response (above the grand mean). G7, G15, G11, G6 and G4 had similar grain yield response (below the grand mean). In contrast, cultivars G5, G14, and 


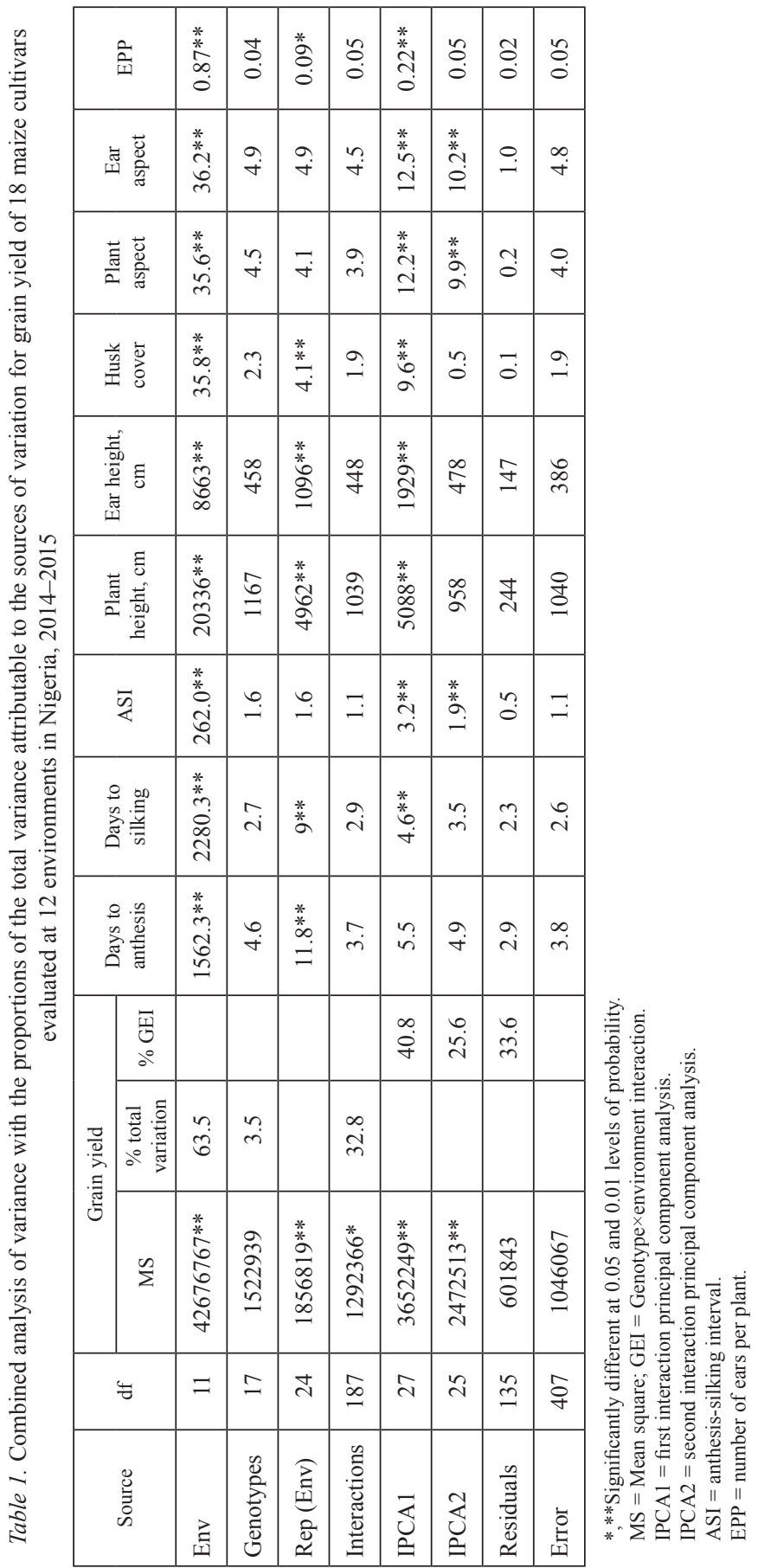




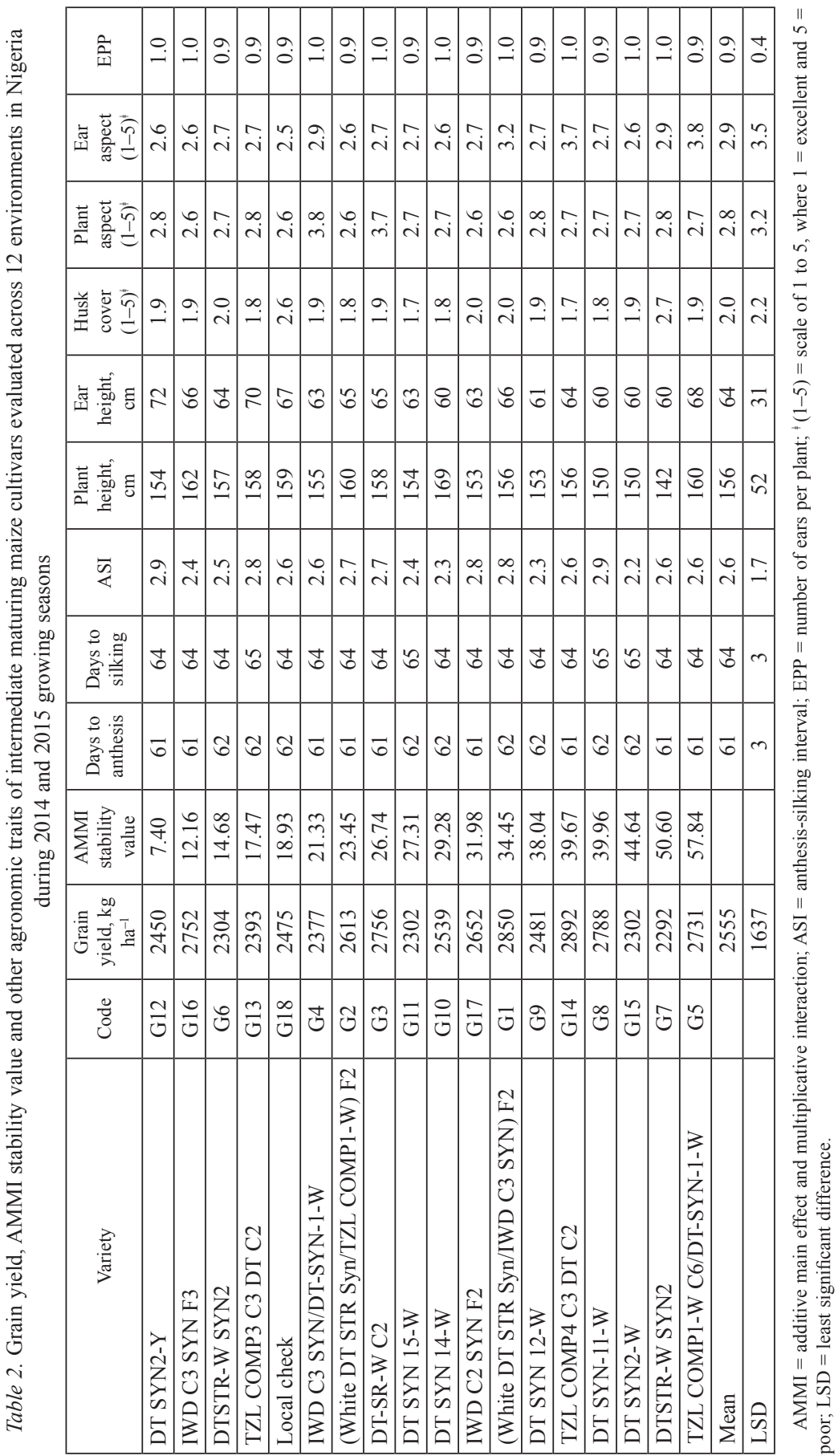


G1 had similar grain yield response (above the grand mean) and strong positive interaction with IPCA1 score and thus, the highest yielding cultivars. G3 and G8, which were comparable with G17 and G2 (above the grand mean), had negative interaction with IPCA1 score, suggesting that important differences exist in the reaction of these cultivars to the different environments. The results of the biplot revealed that 18 cultivars tested in the present study could be classified into four groups based on the mean grain yield and stability on the AMMI biplot (Fig. 1). Group 1 comprised G5, G14, G17, G1, G2, and G16, which had comparable mean grain yield and were similar in their interaction with the different environments; group 2 consisted of G3 and G8; group 3 was composed of G4 and G6; while group 4 consisted of G7, G15, G11, G9, G13, and G18, which were comparable in terms of grain yield and interaction with IPC1 scores. Cultivars G12 and G10 could not be classified into any of the groups.

On the other hand, the test environments could be ranked based on their mean yield on the $\mathrm{x}$-axis of the AMMI biplot (Fig. 1). ZA15, ZA14, and BK14 had the highest location mean, while LA14 and LA15 had the least. ZA15, ZA14, BK14, BK15 and IL15 had environment mean above the grand mean, while BG14, BG15, LE14, LE15, IL14, LA14 and LA15, had less than the grand mean. The test environments could also be grouped into four: Group A composed of ZA15 and BK15. Group B was made up of ZA14, BK14 and IL15. Group C consisted of BG15 and LE15 while group D composed of LA15, LA14, LE14, IL14 and BG14.

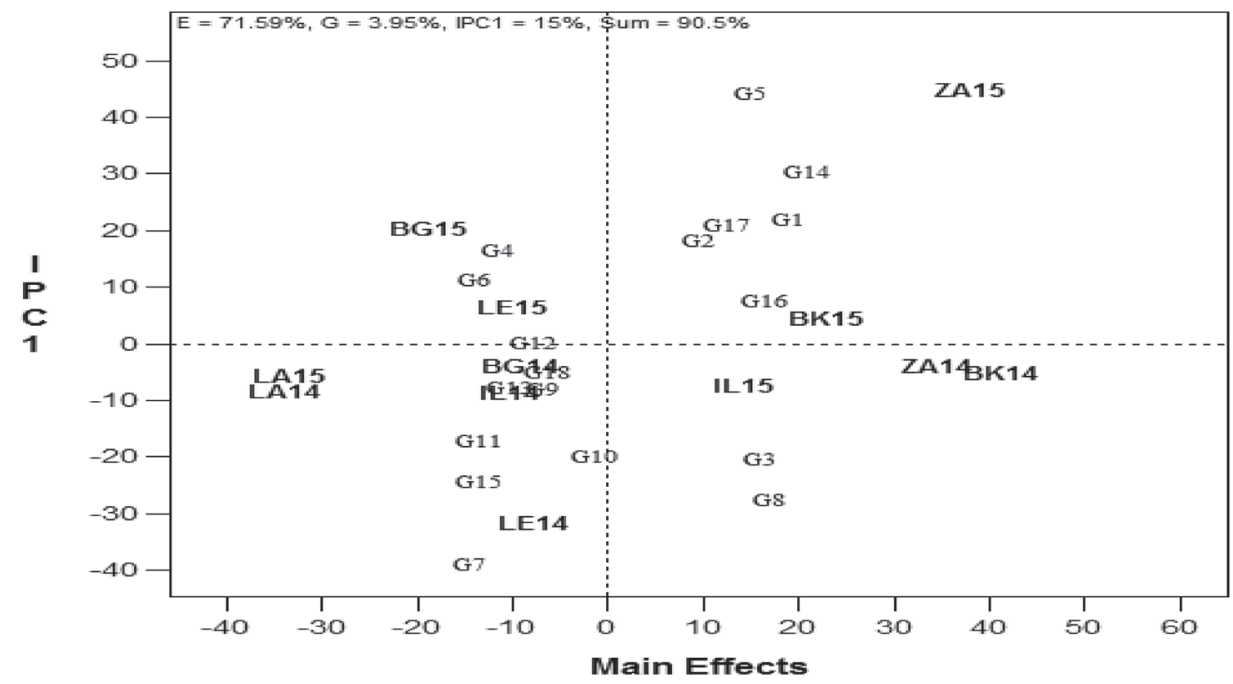

Figure 1. AMMI biplot of grain yield data and the first interaction principal component axis (IPCA 1) of 18 maize cultivars evaluated at 12 environments in Nigeria, 2014-2015. See Table 1 for cultivars legends BG14 and BG15 = Bagauda in 2014 and 2015; ZA14 and ZA15 = Zaria in 2014 and 2015; BK14 and BK15 = Birni Kudu in 2014 and 2015; IL14 and IL15 = Ilorin in 2014 and 2015; LA14 and LA15 = Lapai in 2014 and 2015; and LE14 and LE15 = Lere in 2014 and 2015 


\section{Discussion}

The presence of significant difference for environments in the present study indicated that each environment is unique and the need to identifying the best environments for the identification of high-yielding cultivars for further testing and release in Nigeria. The lack of significant difference among the genotypes is not surprising because the cultivars included in the trials were the top-yielding elite varieties available in the IITA intermediate maize germplasm. However, the differential response of genotypes to varying environmental conditions constitutes a major limitation in the identification of superior maize cultivars for narrow or wide adaptation. The presence of significant GEI for grain yield of the intermediate maturing maize cultivars demonstrated the need for the extensive testing of cultivars in multiple environments over years and the need to identify high-yielding and stable cultivars. This result is in agreement with the findings of earlier workers (BaduApraku et al. 2003; Sabaghnia et al. 2008; Moghaddam and Pourdad 2009).

The high proportion of $63.5 \%$ contributed by environments to the total variation in grain yield, $32.8 \%$ contributed by GEI and low (3.5\%) contribution by genotypes fall within the range reported by earlier workers (Fakorede and Adeyemo 1986; Badu-Apraku et al. 2003, 2011a, b; Mohammadi et al. 2009). However, the contribution of locations to the environmental variation is much higher than the effect of years and location $\times$ year interactions. The results of the present revealed that performance of the cultivars were not consistent for some of the locations in the two years. The inconsistence observed might be due to environmental factors such as amount and distribution of rainfall, solar radiation, temperature, and crop management practices. The contribution of GEI was nearly nine times that of genotypes. The low proportion contributed by genotypic main effect could be due to the comparative yield levels of the elite top-yielding cultivars included in the trials. The high LSD values obtained in the present study could be due to large differences in the performance of the cultivars in some of the locations and years. However, it was interesting to note that cultivar G12 (DT SYN2-Y) had the least AMMI stability value of 7.4 while cultivar G5 (TZL COMP1-W C6/DT-SYN-1-W) had the highest (57.84). Cultivar G12 was the most stable but below grand mean mean while G5 was among the highest-yielding but the most unstable. This result suggests the need not only to consider yield stability but also high-yielding genotypes in cultivar recommendation.

A total of $90.5 \%$ of the treatment sum of squares captured by the AMMI biplot, suggesting the appropriateness of the biplot in explaining both the main effects and providing insight into the GEI. The AMMI biplot revealed differences among the test environments and genotypes and classified them into four groups. The relative closeness of the cultivars G12, G18, G13 and G9, near zero IPCA1, suggest that they have comparable mean grain yields and are similar in their interaction with the different environments, and therefore are the most stable cultivars. The large positive interaction of G5, G14, and G1 with IPCA1 implies that they are probably adapted to favourable environments and thus, the highest yielding cultivars. In contrast, the negative interaction of G7 and G15 suggests that these cultivars are likely to be adapted to low-yielding environments. IWD C3 SYN F3 (G16) was identified as the high-yielding and stable cultivar across environments. 
Test environments in group A were characterized by positive IPCA1 scores with environment means above the grand means and were therefore classified as high-yielding environments. Group B locations had negative or close to zero IPCA1 scores with environment means above the grand means and were therefore high-yielding environments. Both groups, A and B environments except ZA15, had little interaction with genotypes and would rank the genotypes consistently. The implication is that the two groups of environments provided similar information about the genotypes. In contrast, group C environment had a positive IPCA1 score with an environment mean below the grand mean and therefore could be regarded as a low-yielding environment. Similarly, group D environment had a negative IPCA1 score and environment mean below the grand mean and therefore could be regarded as a low-yielding environment. Groups C and D environments except BG15 in group C and LE14 in group D had little interaction with genotypes and would rank the genotypes consistently. The performance of test environments, ZA15, ZA14, BK14, BK15 and IL15 above the grand mean and below grand mean of BG14, BG15, LE14, LE15, IL14, LA14 and LA15 indicated the consistency of performance of $\mathrm{ZA}, \mathrm{BK}, \mathrm{BG}, \mathrm{LE}$ and LA in the two growing seasons. The implication of this result is that Zaria and Birnin Kudu could be used for selecting the superior maize cultivars. The inconsistency of performance of IL14 and IL15 indicated that the test location could be improved to provide reliable data for cultivar selection. The identification of Zaria, Birnin Kudu, and Ilorin with above environment mean was not surprising because Zaria located in the northern Guinea savanna (NGS) which is characterized by moderately high rainfall (1100 mm of rainfall), Birnin Kudu (Sudan-NGS transition zone which is characterised by $1000 \mathrm{~mm}$ of rainfall) and Ilorin (southern Guinea savanna which is characterised by $1200 \mathrm{~mm}$ of rainfall). This result is in agreement with the finding of Oyekunle and BaduApraku (2014), who reported that savannas of West Africa have the greatest potential for maize production and productivities. The identification of Zaria as an outstanding location for identifying superior genotypes in the present study is consistent with the findings of earlier workers (Badu-Apraku et al. 2011a, b)

\section{Acknowledgements}

Financial support of DTMA Project for this study is gratefully acknowledged. The author is also grateful to the staff of the IAR Maize Improvement Program for technical assistance.

\section{References}

Badu-Apraku, B., Abamu, F.J., Menkir, A., Fakorede, M.A.B., Obeng-Antwi, K., The, C. 2003. Genotype by environment interactions in the regional early variety trials in West and Central Africa. Maydica 48:93-104.

Badu-Apraku, B., Lum, A.F., Fakorede M.A.B., Menkir, A., Chabi, Y., The, C., Abdulai, M., Jacob, S., Agbaje, S. 2008. Performance of cultivars derived from recurrent selection for grain yield and striga resistance in early maize. Crop Sci. 48:99-112.

Badu-Apraku, B., Oyekunle, M., Obeng-Antwi, K., Osuman, A., Ado, S.G., Coulibaly, N., Yallou, C., Abdulai, M.S., Boakyewaa, G.A., Didjeira, A. 2011a. Performance of extra-early maize cultivars based on GGE biplot and AMMI analysis. J. Agric. Sci. 150:1-11. 
Badu-Apraku, B., Akinwale, R.O., Menkir, A., Obeng-Antwi, K., Osuman, A.S., Coulibaly, N., Onyibe, J.E. Yallou, G.C., Abdullai, M.S., Didjera, A. 2011b. Use of GGE biplot for targeting early maturing maize cultivars to mega-environments in West Africa. African Crop Sci. J. 19:79-96.

Byerlee, D., Eicher, C.K. 1971. Africa’s Emerging Maize Revolution. Lynne Rienner Publishers. Boulder, CO, USA.

Chang, L., Chai, S.X. 2006. Application of AMMI model in the stability analysis of spring wheat in rainfed area. Acta Ecol. Sin. 26:3677-3684.

Crossa, J. 1990. Statistical analyses of multilocation trials. Adv. Agron. 44:55-85.

Crossa, J., Fox, P.N., Pfeiffer, W.H., Rajaram, S., Gauch, H.G. 1991. AMMI adjustment for statistical analysis of an international wheat yield trial. Theor. Appl. Genet. 81:27-37.

Ejeta, G. 2010. African Green Revolution needn’t be a mirage. Sci. 327:831-832.

Fakorede, M.A.B., Adeyemo, M.O. 1986. Genotype $\times$ environment components of variance for three types of maize varieties in the rainforest zone of S.W. Nigeria. Nigerian J. Agron. 1:43-46.

Fan, X.M., Kang, M.S., Chen, H., Zhang, Y., Tan, J., Xu, C. 2007. Yield stability of maize hybrids evaluated in multi-environment trials in Yunnan, China. Agron. J. 99:220-228.

FAOSTAT 2016. Food and Agriculture Organization of the United Nation Statistics Division. Available at: http://faostat3.fao.org/ download/Q/QC/E (accessed on May 4, 2016).

Gauch, H.G., Zobel, R.W. 1997. Identifying mega-environments and targeting genotypes. Crop Sci. 37:311326.

Gauch, H.G. 1988. Model selection and validation for yield trials with interaction. Biometrics 44:705-715.

Gauch, H.G., Zobel, R.W. 1988. Predictive and postdictive success of statistical analysis of yield trials. Theor. Appl. Genet. 76:1-10.

Gauch, H.G. 1992. Statistical Analysis of Regional Yield Trials: AMMI Analysis of Factorial Designs. Elsevier. Amsterdam, The Netherlands.

Kang, M.S., Balzarini, M.G., Guerra, J.L.L. 2004. Genotype-by-environment interaction. In: Saxton, A.M. (ed.), Genetic Analysis of Complex Traits Using SAS. SAS Publ. SAS Inst. Cary, NC, USA. pp. 69-96.

Liu, W.J., Li, H.J., Wang, X.D., Zhou, K.D. 2002. Stability analysis for elementary characters of hybrid rice by AMMI model. Acta Agron. Sin. 28:569-573.

Moghaddam, M.J., Pourdad, S.S. 2009. Comparison of parametric and non-parametric methods for analyzing genotype $\times$ environment interactions in safflower (Carthamus tinctorius L.). J. Agric. Sci. 147:601-612.

Mohammadi, R., Amri, A., Haghparast, R., Sadeghzadeh, D., Armion, M., Ahmadi, M.M. 2009. Pattern analysis of genotype-by-environment interaction for grain yield in durum wheat. J. Agric. Sci. 147:537-545.

Oyekunle, M., Badu-Apraku, B. 2014. Hybrid performance and inbred-hybrid relationship of early maturing tropical maize under drought and well-watered conditions. Cereal Res. Commun. 42:314-325.

Reddy, P.S., Rathore, A., Reddy, B.V.S., Panwar, S. 2011. Application GGE biplot and AMMI model to evaluate sweet sorghum (Sorghum bicolor) hybrids for genotype $\times$ environment interaction and seasonal adaptation. Indian J. Agri. Sci. 81:438-444.

Sabaghnia, N., Sabaghpour, S.H., Dehghani, H. 2008. The use of an AMMI model and its parameters to analyse yield stability in multi-environment trials. J. Agric. Sci. 146:571-581.

SAS Institute 2002. SAS User's Guide. Version 9.2. SAS Institute Inc. Cary, NC, USA.

Westcoff, B. 1987. A method of analysis of the yield stability of crops. J. Agric. Sci. 108:267-274.

Xu, N.Y., Zhang, G.W., Li, J., Zhou, Z.G. 2013. Ecological regionalization of cotton varieties based on GGE biplot. Chin. J. Appl. Ecol. 24:771-776.

Yan, W.K. 2010. Optimal use of biplots in the analysis of multi-environment variety trial data. Acta Agron. Sin. 36:1-16.

Yan, W. 2001. GGE biplot: a Windows application for graphical analysis of multi-environment trial data and other types of two-way data. Agron. J. 93:1111-1118.

Zobel, R.W., Wright, M.J., Gauch, H.G. 1988. Statistical analysis of a yield trial. Agron. J. 80:388-393. 